\title{
Cross-lingual Evidence Improves Monolingual Fake News Detection
}

\author{
Daryna Dementieva and Alexander Panchenko \\ Skolkovo Institute of Science and Technology, Moscow, Russia \\ \{daryna.dementieva, a.panchenko\}eskoltech.ru
}

\begin{abstract}
Misleading information spreads on the Internet at an incredible speed, which can lead to irreparable consequences in some cases. Therefore, it is becoming essential to develop fake news detection technologies. While substantial work has been done in this direction, one of the limitations of the current approaches is that these models are focused only on one language and do not use multilingual information. In this work, we propose a new technique based on cross-lingual evidence (CE) that can be used for fake news detection and improve existing approaches. The hypothesis of the usage of cross-lingual evidence as a feature for fake news detection is confirmed, firstly, by manual experiment based on a set of known true and fake news. Besides, we compared our fake news classification system based on the proposed feature with several strong baselines on two multi-domain datasets of generaltopic news and one newly fake COVID-19 news dataset showing that combining crosslingual evidence with strong baselines such as RoBERTa yields significant improvements in fake news detection.
\end{abstract}

\section{Introduction}

After the manipulation of opinions on Facebook during the 2016 U.S. election (Allcott and Gentzkow, 2017), the interest in the topic of fake news has increased substantially. Unfortunately, the distribution of fakes leads not only to misinformation of readers but also to more severe consequences such as shooting in Washington Pizzeria (Kang and Goldman, 2016) that was caused by the spreading of fake news about Hillary Clinton leading a child sex trafficking. Also, due to the global pandemic in 2020, there was a simultaneous emergence of infodemic (Alam et al., 2020) that could lead to an even worse epidemiological situation and harm people's health dramatically.
As a result, fake news received tremendous public attention, as well as drawn increasing interest from the academic community. Multiple supervised fake news detection models were proposed based on linguistic features (Pérez-Rosas et al., 2018; Patwa et al., 2020); deep learning models (Barrón-Cedeño et al., 2019; Glazkova et al., 2020; Kaliyar et al., 2021); or signals from social networks (Nguyen et al., 2020; Cui et al., 2019). One of the directions of the supervised approaches is to use additional information from the Web (Popat et al., 2017; Karadzhov et al., 2017; Ghanem et al., 2018). However, in these works only monolingual signals were taken into account.

In our work, we assume that viral spreading of (fake) information may naturally hit the "language barrier" and cross-checking of facts across media in various languages (supposed to be strongly independent) could yield an additional signal. We aim to close this gap and perform an exploration of cross-lingual Web features to fake news detection.

The contribution of our work is a new crosslingual evidence feature for fake news detection based on multilingual news verification. ${ }^{1}$ We conduct a manual experiment based on cross-lingual dataset markup to evaluate if the user can use such a feature for misinformation identification. After that, we implement the proposed feature showing that adding cross-lingual evidence consistently improves the results of strong baselines including large pre-trained transformers. We release publicly all code and data. ${ }^{2}$

\section{Related Work}

Firstly, several datasets have been collected for different sub-tasks of fake news detection pipeline:

\footnotetext{
${ }^{1}$ This work is a substantially extended version of the preliminary experiment by Dementieva and Panchenko (2020).

${ }^{2}$ https://github.com/skoltech-nlp/ multilingual-fake-news
} 


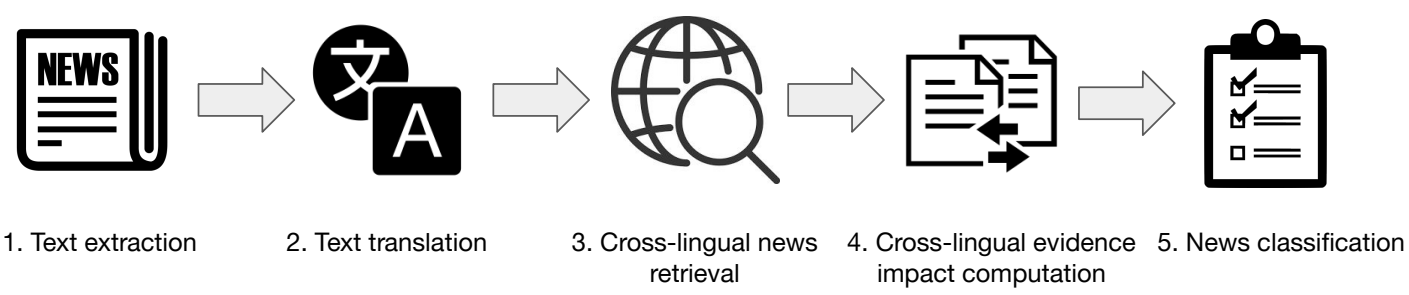

Figure 1 - Overview of our approach: checking for fake news based on cross-lingual evidence (CE).

dataset from The Fake News Challenge $e^{3}$ for stance detection; LIAR (Wang, 2017), FakeNewsNet (Shu et al., 2018), FakeNewsDatasets (Pérez-Rosas et al., 2018), and NELA-GT-2018 (Norregaard et al., 2019) for fake news classification tasks; FEVER (Thorne et al., 2018) for fact checking tasks. Responding to current events in 2020, COVID-19 fake news classification datasets COVID-19 Fake News (Patwa et al., 2020), ReCOVery (Zhou et al., 2020) have been already created.

Several supervised models were previously explored. Some of the works focused on exploring internal features of news. In (Pérez-Rosas et al., 2018; Patwa et al., 2020) different linguistic features extracted from news texts were used. In (Ghanem et al., 2020) the perspective of the usage of emotional signals extracted from the news text for detecting fakes was shown. In addition to internal features, a set of external features can add more confidence in fake news detection model decision reasoning. For instance, user interaction signals were explored in (Nguyen et al., 2020; Cui et al., 2019). Another quite strong signal can be additional information extracted from the Web. In (Popat et al., 2017; Karadzhov et al., 2017; Ghanem et al., 2018; Li and Zhou, 2020) the authors referred to the Web search (Google or Bing) to collect relevant articles and use such scraped information as an external feature to build a fake news classifier.

Seeking information via some search engine to find evidence is a quite natural feature motivated by real users' behaviour. Several studies tried to figure out how users authenticate the information from the Web. Jr. et al. (2018) showed that individuals rely on both their judgment of the source and the message, and when this does not adequately provide a definitive answer, they turn to external resources to authenticate news. The intentional and institutional reaction was seeking confirmation from institutional sources (some respondents answered simply "Google"). Moreover, participants that received messages across different media plat-

\footnotetext{
${ }^{3}$ http://www. fakenewschallenge.org
}

forms (Zhao, 2019) and different perspectives of the information (Geeng et al., 2020) showed greater awareness about news evidence. Consequently, the information from the external search is an important feature for news authenticity evaluation and evidence seeking. While the idea of multilingualism was already explored for hate speech (Aluru et al., 2020) and rumors (Wen et al., 2018) detection, however, previous works did not fully use multilingual information of fake news detection. In our study, we explore fake news spread on the Web for different languages and extend evidence retrieval to cross-lingual news verification.

\section{Detection of Fake News using Cross-lingual Evidence (CE)}

Our approach is based on the following hypothesis: if the news is true, then it will be widespread in different languages and also across media with different biases, and the facts mentioned should be identical. On the other hand, if it is fake news, it will receive a lesser response in the foreign press than true news. The step-by-step process, schematically represented in Figure 1, is as follows:

Step 1. Text extraction: As a new article arrives, title and content are extracted from it.

Step 2. Text translation: The title is translated into target languages and new search requests are generated.

Step 3. Cross-lingual news retrieval: Search is executed based on the translated titles in multiple languages.

Step 4. Cross-lingual evidence impact computation Top-N articles from search results are used to evaluate the authenticity of the initial news. The information described in the news is compared with the information in the articles from the search result. The number of articles that confirms or disproves the original news is estimated.

Step 5. News classification: Based on the information from the previous step, the decision is made about the authenticity of the news. If the majority of results support the original news, then it is more 
likely to be true; if there are contradictions - it is a signal to consider the news as fake.

To confirm the hypothesis that cross-lingual evidence can be used for fake news detection we conducted two experiments. The first one (Section 4) is a manual small-scale study confirming the hypothesis that a person can distinguish fake news based on such cross-lingual evidence. The second one (Section 5) is an automated fake news detection system tested on several fake news datasets: we implemented our cross-lingual evidence feature and compared it with several baselines achieving SOTA on all datasets.

\section{Experiment 1: Manual Verification}

First, we conducted a manual experiment on a small dataset to test the hypothesis in "ideal conditions".

\subsection{Dataset}

For fake news examples, we used the list of top 50 fake news from 2018 according to BuzzFeed. ${ }^{4}$. For true news, we used NELA-GT-2018 dataset (Norregaard et al., 2019). We manually selected 10 fake and true news and manually executed all steps of our approach (Section 3) on this dataset. This dataset featuring 20 news is provided in Table 2 in the Appendix A: the dataset is combined by news from several fields - celebrities, science, politics, culture, and world.

\subsection{Experimental Setup}

We precalculated Step 2 and Step 3 for annotators convenience and reproducibility. We generated cross-lingual requests in five languages - English, French, German, Spanish, and Russian. For translation from English, Google Translation service was used. As all news are of 2018, the time range of every search was limited only by this year. From search results, we used the first page of the search which consisted of 10 news. As a result, for 20 news for each of languages we got 1000 pairs of "original news $\leftrightarrow$ scraped news" to markup.

We asked 6 annotators to take part in the experiment: manually conduct Step 4: cross-lingual evidence impact computation. For each news, we provide information about its title, content, and link of the source. Every annotator got 10 randomly selected news, as a result, we got each news crosschecked by 3 annotators. All non-English news

\footnotetext{
${ }^{4}$ https: / / github.com/BuzzFeedNews / 2018-12-fake-news-top-50
}

were translated into English. For each pair "original news $\leftrightarrow$ scraped news" the annotator provided one of three answers: 1) Support: the information in the scraped news supports the original news; 2 ) Refute: the information is opposite or differ from the original news or there is an explicit refutation; 3) Not enough info: the information is not relevant or not sufficient to support/refute the original news. Finally, at the end of the annotation of a sample, the annotator was asked to conduct Step 5 of the pipeline and classify the news as fake or true.

The used interface for manual markup is presented in Appendix A Figure 3.
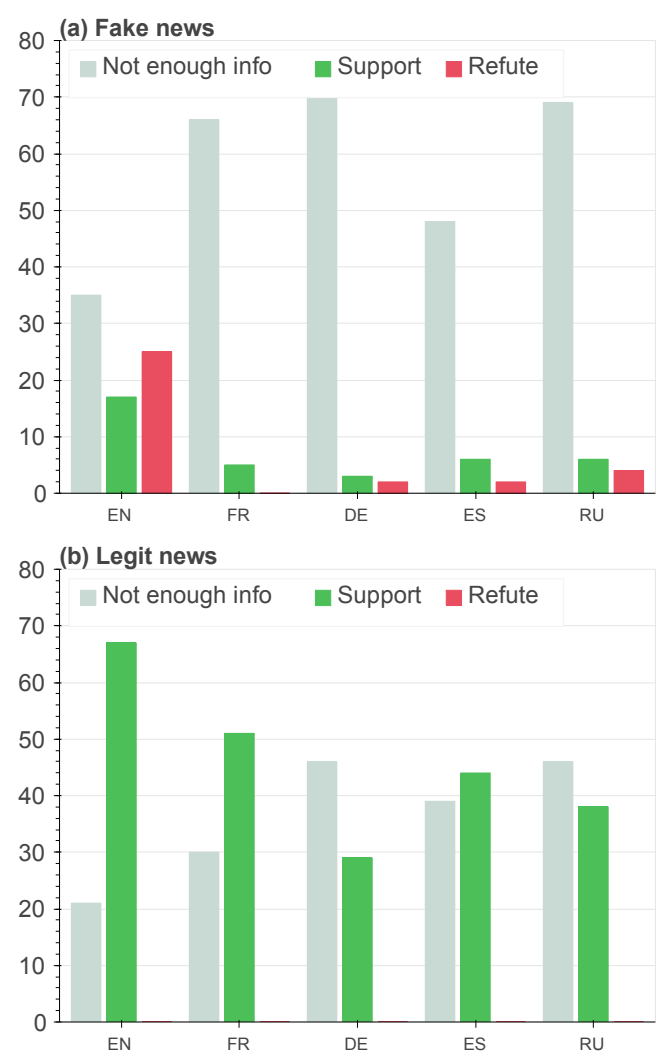

Figure 2 - The results of manual annotation: the distribution of annotators answers for fake (a) and legit (b) news.

\subsection{Discussion of Results}

Based on the collected annotations, for each news we chose the final label based on the majority voted. We estimated confidence in the annotators' agreement with Krippendorff's alpha $(\alpha=0.83)$. After that, we calculated the distribution of each type of annotators' answers for the top 10 search results by language for fake and true news separately. The results are provided in Figure 2.

As we can see, the distribution of labels for true news significantly differs from the distribution for fake ones: the number of supporting articles is 


\begin{tabular}{|c|c|c|c|c|c|c|c|c|c|}
\hline & \multicolumn{3}{|c|}{ FakeNewsAMT } & \multicolumn{3}{|c|}{ Celebrity } & \multicolumn{3}{|c|}{ ReCOVery } \\
\hline & Pre. & Rec. & $\mathrm{F} 1$ & Pre. & Rec. & F1 & Pre. & Rec. & F1 \\
\hline TextCNN & 0.276 & 0.250 & 0.260 & 0.641 & 0.703 & 0.664 & 0.733 & 0.913 & 0.805 \\
\hline LSTM & 0.614 & 0.614 & 0.614 & 0.745 & 0.740 & 0.740 & 0.800 & 0.803 & 0.793 \\
\hline ME Sim + ME AlexaRank & 0.539 & 0.593 & 0.592 & 0.552 & 0.550 & 0.550 & 0.794 & 0.798 & 0.793 \\
\hline CE AlexaRank & 0.541 & 0.541 & 0.541 & 0.605 & 0.605 & 0.605 & 0.768 & 0.773 & 0.765 \\
\hline CE Sim + CE AlexaRank & 0.872 & 0.864 & 0.864 & 0.631 & 0.620 & 0.619 & 0.829 & 0.829 & 0.829 \\
\hline BERT & 0.586 & 0.586 & 0.586 & 0.800 & 0.800 & 0.800 & 0.868 & 0.868 & 0.866 \\
\hline BERT + CE AlexaRank & 0.541 & 0.541 & 0.541 & 0.810 & 0.728 & 0.915 & 0.768 & 0.773 & 0.765 \\
\hline BERT + CE Sim + CE AlexaRank & 0.884 & 0.885 & 0.894 & $\underline{0.982}$ & $\underline{0.982}$ & $\underline{0.982}$ & 0.870 & 0.863 & $\mathbf{0 . 8 8 4}$ \\
\hline RoBERTa & 0.895 & 0.548 & 0.656 & 0.856 & 0.690 & 0.731 & 0.986 & 0.936 & 0.956 \\
\hline RoBERTa + CE AlexaRank & 0.930 & 0.820 & 0.872 & 0.799 & 0.890 & 0.822 & 0.949 & $\underline{0.986}$ & 0.966 \\
\hline RoBERTa + CE Sim + CE AlexaRank & $\underline{0.973}$ & $\underline{0.938}$ & $\underline{0.953}$ & 0.952 & 0.784 & 0.856 & $\underline{0.992}$ & $\overline{0.960}$ & $\underline{0.975}$ \\
\hline Ngram & 0.573 & 0.572 & 0.572 & 0.730 & 0.730 & 0.730 & 0.878 & 0.879 & 0.877 \\
\hline Ngrams + CE AlexaRank & 0.655 & 0.655 & 0.655 & 0.740 & 0.740 & 0.740 & 0.891 & 0.891 & 0.891 \\
\hline Ngrams + CE Sim + CE AlexaRank & 0.864 & 0.854 & 0.853 & $\mathbf{0 . 7 8 9}$ & $\mathbf{0 . 7 9 0}$ & 0.789 & 0.931 & 0.932 & 0.931 \\
\hline Punctuation & 0.239 & 0.489 & 0.321 & 0.211 & 0.460 & 0.289 & 0.433 & 0.658 & 0.522 \\
\hline Punctuation + CE AlexaRank & 0.741 & 0.741 & 0.741 & 0.605 & 0.600 & 0.600 & 0.668 & 0.673 & 0.665 \\
\hline Punctuation + CE Sim + CE AlexaRank & 0.872 & 0.864 & 0.864 & 0.631 & 0.620 & 0.619 & 0.829 & 0.829 & 0.829 \\
\hline LIWC & 0.597 & 0.593 & 0.592 & 0.630 & 0.610 & 0.605 & 0.768 & 0.771 & 0.756 \\
\hline LIWC + CE AlexaRank & 0.646 & 0.645 & 0.644 & 0.712 & 0.700 & 0.690 & 0.846 & 0.846 & 0.842 \\
\hline LIWC + CE Sim + CE AlexaRank & 0.894 & 0.885 & 0.884 & 0.692 & 0.680 & 0.679 & 0.894 & 0.894 & 0.894 \\
\hline Readability & 0.729 & 0.729 & 0.729 & 0.478 & 0.470 & 0.468 & 0.732 & 0.741 & 0.724 \\
\hline Readibility + CE AlexaRank & 0.760 & 0.760 & 0.760 & 0.592 & 0.590 & 0.590 & 0.796 & 0.798 & 0.790 \\
\hline Readability + CE Sim + CE AlexaRank & 0.928 & 0.927 & 0.927 & 0.674 & 0.670 & 0.670 & 0.828 & 0.829 & 0.828 \\
\hline Syntax & 0.626 & 0.625 & 0.624 & 0.639 & 0.630 & 0.629 & 0.812 & 0.809 & 0.797 \\
\hline Syntax + CE AlexaRank & 0.677 & 0.677 & 0.677 & 0.721 & 0.720 & 0.720 & 0.844 & 0.841 & 0.834 \\
\hline Syntax + CE Sim + CE AlexaRank & 0.902 & 0.895 & 0.895 & 0.754 & 0.750 & 0.750 & 0.886 & 0.886 & 0.886 \\
\hline All lingui & 0.739 & 0.739 & 0.739 & 0.750 & 0.750 & 0.750 & 0.875 & 0.874 & 0.870 \\
\hline All linguistic + CE AlexaRank & 0.641 & 0.641 & 0.641 & 0.605 & 0.600 & 0.600 & 0.868 & 0.868 & 0.868 \\
\hline All linguistic + CE Sim + CE AlexaRank & 0.940 & 0.937 & $\mathbf{0 . 9 3 7}$ & 0.801 & 0.800 & 0.800 & 0.916 & 0.917 & 0.916 \\
\hline
\end{tabular}

Table 1 - Results: adding our Cross-lingual Evidence (CE) improves various baseline systems and yields state-of-the-art results. The proposed feature is used in two parts: (i) content similarity score based on embeddings distance (Sim); (ii) AlexaRank score of the scraped news source (AlexaRank). ME stands for Monolingual Evidence. The statistical significance of the baselines improvements was tested with paired t-test over 5-fold cross-validation.

enough for almost every language. At the same time, for fake news we got more refuting signals than supporting for the English language and little or no evidence or relevant information dissemination for other languages. The average accuracy of annotators classification is 0.95 . Thus, a person can distinguish fake based on cross-lingual evidence.

\section{Experiment 2: Automatic Verification}

We implemented cross-lingual evidence (CE) feature, as described below. We tested its performance on fake news detection on three multi-domain datasets comparing it with strong baselines.

\subsection{Cross-lingual Evidence (CE) Feature}

Cross-lingual evidence retrieval As in manual setup, for translation and search we used Google services via Python APIs. In our setup for the automated feature we focused as well on five languages:
English, French, German, Spanish, and Russian. We extracted only the first page of the search result that gave us 10 articles for each language.

Cross-lingual text similarity For unsupervised cross-lingual relevance computation between original news and scraped one, we chose cosine similarity between sentence embeddings. To get sentence vector representation, we averaged the both title and content sentence's tokens' embeddings extracted from M-BERT (Devlin et al., 2019). For the sample news the similarity score is extracted for all 10 pairs "original news $\leftrightarrow$ scraped news" for each of 5 languages.

Source credibility Also, we took into account the credibility of the source. Following Popat et al. (2016) we used AlexaRank for source assessment.

Cross-lingual evidence (CE) feature is constructed of two parts: content similarity score based 
on embeddings distance (Sim) and AlexaRank score of the scraped news source (AlexaRank).

\subsection{Datasets}

Firstly, we evaluate the systems on a multi-domain dataset by Pérez-Rosas et al. (2018) which consist of two parts: FakeNewsAMT dataset (240 fake and 240 legit articles) and CelebrityDataset dataset (250 fake and 250 legit articles). FakeNewsAMT dataset consists of news from six topics: sports, business, entertainment, politics, technology, and education. CelebrityDataset is dedicated to rumors, hoaxes, and fake reports about famous actors, singers, socialites, and politicians. Secondly, we ran experiments on COVID-19 fake news dataset ReCOVery (Zhou et al., 2020). It consists of 2029 (665 fake and 1364 true news). All datasets are originally in English. We used 70\%-20\%-10\% proportion for train-test-validation split.

\subsection{Baselines}

We compare to both linguistic-based fake news detection models and SOTA deep neural networks:

Linguistic Features: In (Pérez-Rosas et al., 2018) a baseline fake news classification model was trained based on Ngrams, punctuation, psycholinguistic features extracted with LIWC, readability, syntax, and concatenation of all these set of features. In (Zhou et al., 2020) LIWC features were also used as one of the proposed baselines. We tested these features separately, grouped them all, and in combination with our proposed feature. We experimented with SVM, RandomForest, LogRegression, and LightGBM. The best models based on LightGBM are presented.

Text-CNN, LSTM: Following (Zhou et al., 2020), we tested TextCNN and LSTM models on all datasets. We fined-tuned models hyperparameters and report the best ones in the results.

BERT, RoBERTa: BERT (Devlin et al., 2019) based models were used for fake news detection by Kaliyar et al. (2021) and specifically for COVID19 fake news classification (Gundapu and Mamidi, 2021; Glazkova et al., 2020). We used pretrained models and fine-tuned them. The combination with $\mathrm{CE}$ feature was done as a concatenation with [CLS] token embedding before Linear layer.

Monolingual Evidence (ME): In addition, we compared our feature with the case when only monolingual English evidence was used. The LightGBM classification model was used as well.

\subsection{Discussion of Results}

Table 1 compares results of our model based on cross-lingual evidence (CE) with the baselines on three datasets. The statistical significance of the baselines improvements was tested with paired t-test over 5-fold cross-validation. The CE feature by itself outperforms all baseline for FakeNewsAMT and better than some linguistic features for Celebrity and ReCOVery. The monolingual English evidence (ME) works worse than the cross-lingual one. The usage of only rank feature improves the baselines, but the best scores are achieved by adding full $\mathrm{CE}$ features set. The combinations of CE feature with BERT and RoBERTa gains SOTA results for all dataset. At the same time, despite linguistic features did not outperform Transformer-based baselines, the combination of our CE feature and different linguistic features showed competitive results that can be more explainable than the transformer model. Examples how retrieved cross-lingual results can be used to explain the classification results are illustrated in Appendix B.

\section{Conclusion}

We presented an approach for fake news detection based on cross-lingual evidence (CE) which provides a different perspective on the event across languages verified in two experiments. A fake news classification model with CE significantly improves performance over various baselines and compares favorably to SOTA. Besides, the CE is interpretable as a user can check in which and how many languages a piece of given news was found.

A promising direction to explore is to increase the number of languages used for cross-lingual information retrieval. In addition to this, the general distribution of news in the world should be taken into account - for instance, US news tend to be covered in European presses more than European news are covered in the US press. Also, in our work the language of original news was English. The analogous experiments for other original languages of news should be conducted.

\section{Acknowledgments}

We thank anonymous reviewers for their thorough comments and suggestions for future work. The work has been conducted in the framework of the joint MTS-Skoltech laboratory. 


\section{References}

Firoj Alam, Fahim Dalvi, Shaden Shaar, Nadir Durrani, Hamdy Mubarak, Alex Nikolov, Giovanni Da San Martino, Ahmed Abdelali, Hassan Sajjad, Kareem Darwish, and Preslav Nakov. 2020. Fighting the COVID-19 infodemic in social media: A holistic perspective and a call to arms. CoRR, abs/2007.07996.

Hunt Allcott and Matthew Gentzkow. 2017. Social media and fake news in the 2016 election. Journal of economic perspectives, 31(2):211-36.

Sai Saketh Aluru, Binny Mathew, Punyajoy Saha, and Animesh Mukherjee. 2020. Deep learning models for multilingual hate speech detection. CoRR, abs/2004.06465.

Alberto Barrón-Cedeño, Israa Jaradat, Giovanni Da San Martino, and Preslav Nakov. 2019. Proppy: Organizing the news based on their propagandistic content. Inf. Process. Manag., 56(5):1849-1864.

Limeng Cui, Kai Shu, Suhang Wang, Dongwon Lee, and Huan Liu. 2019. defend: A system for explainable fake news detection. In Proceedings of the 28th ACM International Conference on Information and Knowledge Management, CIKM 2019, Beijing, China, November 3-7, 2019, pages 2961-2964. ACM.

Daryna Dementieva and Alexander Panchenko. 2020. Fake news detection using multilingual evidence. In 7th IEEE International Conference on Data Science and Advanced Analytics, DSAA 2020, Sydney, Australia, October 6-9, 2020, pages 775-776. IEEE.

Jacob Devlin, Ming-Wei Chang, Kenton Lee, and Kristina Toutanova. 2019. BERT: Pre-training of deep bidirectional transformers for language understanding. In Proceedings of the 2019 Conference of the North American Chapter of the Association for Computational Linguistics: Human Language Technologies, Volume 1 (Long and Short Papers), pages 4171-4186, Minneapolis, Minnesota. Association for Computational Linguistics.

Christine Geeng, Savanna Yee, and Franziska Roesner. 2020. Fake news on facebook and twitter: Investigating how people (don't) investigate. In $\mathrm{CHI}$ '20: CHI Conference on Human Factors in Computing Systems, Honolulu, HI, USA, April 25-30, 2020, pages 1-14. ACM.

Bilal Ghanem, Manuel Montes-y Gòmez, Francisco Rangel, and Paolo Rosso. 2018. Upv-inaoeautoritas-check that: An approach based on external sources to detect claims credibility. In Proceedings of the Conference and Labs of the Evaluation Forum (CLEF'18).

Bilal Ghanem, Paolo Rosso, and Francisco M. Rangel Pardo. 2020. An emotional analysis of false information in social media and news articles. ACM Trans. Internet Techn., 20(2):19:1-19:18.
Anna Glazkova, Maksim Glazkov, and Timofey Trifonov. 2020. g2tmn at constraint@aaai2021: Exploiting CT-BERT and ensembling learning for COVID-19 fake news detection. CoRR, abs/2012.11967.

Sunil Gundapu and Radhika Mamidi. 2021. Transformer based automatic COVID-19 fake news detection system. CoRR, abs/2101.00180.

Edson C. Tandoc Jr., Richard Ling, Oscar Westlund, Andrew Duffy, Debbie Goh, and Lim Zheng Wei. 2018. Audiences' acts of authentication in the age of fake news: A conceptual framework. New Media Soc., 20(8):2745-2763.

Rohit Kumar Kaliyar, Anurag Goswami, and Pratik Narang. 2021. Fakebert: Fake news detection in social media with a bert-based deep learning approach. Multim. Tools Appl., 80(8):11765-11788.

Cecilia Kang and Adam Goldman. 2016. In washington pizzeria attack, fake news brought real guns. New York Times, 5.

Georgi Karadzhov, Preslav Nakov, Lluís Màrquez, Alberto Barrón-Cedeño, and Ivan Koychev. 2017. Fully automated fact checking using external sources. In Proceedings of the International Conference Recent Advances in Natural Language Processing, RANLP 2017, pages 344-353, Varna, Bulgaria. INCOMA Ltd.

Qifei Li and Wangchunshu Zhou. 2020. Connecting the dots between fact verification and fake news detection. In Proceedings of the 28th International Conference on Computational Linguistics, pages 1820-1825, Barcelona, Spain (Online). International Committee on Computational Linguistics.

Van-Hoang Nguyen, Kazunari Sugiyama, Preslav Nakov, and Min-Yen Kan. 2020. FANG: leveraging social context for fake news detection using graph representation. In $C I K M$ '20: The 29th ACM International Conference on Information and Knowledge Management, Virtual Event, Ireland, October 19-23, 2020, pages 1165-1174. ACM.

Jeppe Norregaard, Benjamin D. Horne, and Sibel Adali. 2019. NELA-GT-2018: A large multi-labelled news dataset for the study of misinformation in news articles. CoRR, abs/1904.01546.

Parth Patwa, Shivam Sharma, PYKL Srinivas, Vineeth Guptha, Gitanjali Kumari, Md. Shad Akhtar, Asif Ekbal, Amitava Das, and Tanmoy Chakraborty. 2020. Fighting an infodemic: COVID-19 fake news dataset. CoRR, abs/2011.03327.

Verónica Pérez-Rosas, Bennett Kleinberg, Alexandra Lefevre, and Rada Mihalcea. 2018. Automatic detection of fake news. In Proceedings of the 27th International Conference on Computational Linguistics, COLING 2018, Santa Fe, New Mexico, USA, August 20-26, 2018, pages 3391-3401. Association for Computational Linguistics. 
Kashyap Popat, Subhabrata Mukherjee, Jannik Strötgen, and Gerhard Weikum. 2016. Credibility assessment of textual claims on the web. In Proceedings of the 25th ACM International Conference on Information and Knowledge Management, CIKM 2016, Indianapolis, IN, USA, October 24-28, 2016, pages 2173-2178. ACM.

Kashyap Popat, Subhabrata Mukherjee, Jannik Strötgen, and Gerhard Weikum. 2017. Where the truth lies: Explaining the credibility of emerging claims on the web and social media. In Proceedings of the 26th International Conference on World Wide Web Companion, Perth, Australia, April 3-7, 2017, pages 1003-1012. ACM.

Kai Shu, Deepak Mahudeswaran, Suhang Wang, Dongwon Lee, and Huan Liu. 2018. Fakenewsnet: A data repository with news content, social context and dynamic information for studying fake news on social media. CoRR, abs/1809.01286.

James Thorne, Andreas Vlachos, Christos Christodoulopoulos, and Arpit Mittal. 2018 FEVER: a large-scale dataset for fact extraction and VERification. In Proceedings of the 2018 Conference of the North American Chapter of the Association for Computational Linguistics: Human Language Technologies, Volume 1 (Long Papers), pages 809-819, New Orleans, Louisiana. Association for Computational Linguistics.

William Yang Wang. 2017. "liar, liar pants on fire": A new benchmark dataset for fake news detection. In Proceedings of the 55th Annual Meeting of the Association for Computational Linguistics (Volume 2 . Short Papers), pages 422-426, Vancouver, Canada. Association for Computational Linguistics.

Weiming Wen, Songwen Su, and Zhou Yu. 2018. Cross-lingual cross-platform rumor verification pivoting on multimedia content. In Proceedings of the 2018 Conference on Empirical Methods in Natural Language Processing, pages 3487-3496, Brussels, Belgium. Association for Computational Linguistics.

Wenqing Zhao. 2019. Misinformation correction across social media platforms. In 2019 International Conference on Computational Science and Computational Intelligence (CSCI), pages 1371-1376. IEEE.

Xinyi Zhou, Apurva Mulay, Emilio Ferrara, and Reza Zafarani. 2020. Recovery: A multimodal repository for COVID-19 news credibility research. In CIKM '20: The 29th ACM International Conference on Information and Knowledge Management, Virtual Event, Ireland, October 19-23, 2020, pages 3205-3212. ACM. 


\section{A Manual Evaluation}

\begin{tabular}{|c|c|c|}
\hline News title & URL & Label \\
\hline $\begin{array}{l}\text { Lottery winner arrested for dumping } \$ 200,000 \text { of ma- } \\
\text { nure on ex-boss' lawn }\end{array}$ & $\begin{array}{l}\text { https://worldnewsdailyreport.com/lottery-winner- } \\
\text { arrested-for-dumping-200000-of-manure-on-ex-boss- } \\
\text { lawn/ }\end{array}$ & Fake \\
\hline $\begin{array}{l}\text { Woman sues Samsung for } \$ 1.8 \mathrm{M} \text { after cell phone gets } \\
\text { stuck inside her vagina }\end{array}$ & $\begin{array}{l}\text { https://worldnewsdailyreport.com/woman-sues-samsung- } \\
\text { for-1-8m-after-cell-phone-gets-stuck-inside-her- } \\
\text { vagina/comment-page-58/ }\end{array}$ & Fake \\
\hline $\begin{array}{l}\text { BREAKING: Michael Jordan Resigns From The } \\
\text { Board At Nike-Takes 'Air Jordans' With Him }\end{array}$ & $\begin{array}{l}\text { https://www.newsbreak.com/news/944830700924/breaking- } \\
\text { michael-jordan-resigns-from-the-board-at-nike-takes-air- } \\
\text { jordans-with-him }\end{array}$ & Fake \\
\hline $\begin{array}{l}\text { Donald Trump Ends School Shootings By Banning } \\
\text { Schools }\end{array}$ & $\begin{array}{l}\text { https://www.8shit.net/donald-trump-ends-school- } \\
\text { shootings-banning-schools/ }\end{array}$ & Fake \\
\hline $\begin{array}{l}\text { New mosquito species discovered that can get you } \\
\text { pregnant with a single bite }\end{array}$ & $\begin{array}{l}\text { https://thereisnews.com/new-mosquito-species- } \\
\text { discovered-can-make-you-pregnant/ }\end{array}$ & Fake \\
\hline $\begin{array}{l}\text { Obama Announces Bid To Become UN Secretary Gen- } \\
\text { eral }\end{array}$ & https://www.pinterest.com/pin/465630048969491948/ & Fake \\
\hline $\begin{array}{l}\text { Lil Tay Rushed To Hospital After Being Beat By } \\
\text { Group Of Children At A Playground }\end{array}$ & $\begin{array}{l}\text { https://www.huzlers.com/lil-tay-rushed-to-hospital-after- } \\
\text { being-beat-by-group-of-children-at-a-playground/ }\end{array}$ & Fake \\
\hline $\begin{array}{l}\text { Post Malone's Tour Manager Quits Says Post Malone } \\
\text { Smells Like Expired Milk And Moldy Cheese }\end{array}$ & $\begin{array}{l}\text { https://www.huzlers.com/post-malones-tour-manager- } \\
\text { quits-says-post-malone-smells-like-expired-milk-and- } \\
\text { moldy-cheese/ }\end{array}$ & Fake \\
\hline $\begin{array}{l}\text { Putin: Clinton Illegally Accepted } \$ 400 \text { Million From } \\
\text { Russia During Election }\end{array}$ & $\begin{array}{l}\text { https://newspunch.com/putin-clinton-campaign-400- } \\
\text { million-russia/ }\end{array}$ & Fake \\
\hline $\begin{array}{l}\text { Elon Musk: } 99.9 \% \text { Of Media Is Owned By The 'New } \\
\text { World Order' }\end{array}$ & $\begin{array}{l}\text { https://newspunch.com/elon-musk-media-owned-new- } \\
\text { world-order/ }\end{array}$ & Fake \\
\hline $\begin{array}{l}\text { Scientists Develop New Method to Create Stem Cells } \\
\text { Without Killing Human Embryos }\end{array}$ & $\begin{array}{l}\text { https://www.christianpost.com/news/scientists-develop- } \\
\text { new-method-to-create-stem-cells-without-killing-human- } \\
\text { embryos.html }\end{array}$ & Legit \\
\hline Luis Palau Diagnosed With Stage 4 Lung Cancer & $\begin{array}{l}\text { https://cnnw.com/luis-palau-diagnosed-with-stage-4- } \\
\text { lung-cancer/ }\end{array}$ & Legit \\
\hline $\begin{array}{l}\text { 1st black woman nominated to be Marine brigadier } \\
\text { general }\end{array}$ & $\begin{array}{l}\text { https://edition.cnn.com/2018/04/12/politics/marine- } \\
\text { corps-brigadier-general-first-black-female/index.html }\end{array}$ & Legit \\
\hline $\begin{array}{l}\text { Disney CEO Bob Iger revealed that he seriously ex- } \\
\text { plored running for president }\end{array}$ & $\begin{array}{l}\text { https://www.businessinsider.com/disney-ceo-bob-iger- } \\
\text { says-he-considered-running-for-president-oprah-pushed- } \\
2018-4\end{array}$ & Legit \\
\hline $\begin{array}{l}\text { Trump Has Canceled Via Twitter His G20 Meeting } \\
\text { With Vladimir Putin }\end{array}$ & $\begin{array}{l}\text { https://www.buzzfeednews.com/article/emilytamkin/trump- } \\
\text { g20-putin-russia }\end{array}$ & Legit \\
\hline US Mexico and Canada sign new USMCA trade deal & $\begin{array}{l}\text { https://www.dw.com/en/us-mexico-canada-sign-usmca- } \\
\text { trade-deal/a-51613992 }\end{array}$ & Legit \\
\hline $\begin{array}{l}\text { Afghanistan Women children among } 23 \text { killed in US } \\
\text { attack UN }\end{array}$ & $\begin{array}{l}\text { https://www.aljazeera.com/news/2018/11/30/afghanistan- } \\
\text { women-children-among-23-killed-in-us-attack-un }\end{array}$ & Legit \\
\hline $\begin{array}{l}\text { UNESCO adds reggae music to global cultural her- } \\
\text { itage list }\end{array}$ & $\begin{array}{l}\text { https://www.aljazeera.com/features/2018/11/29/unesco- } \\
\text { adds-reggae-music-to-global-cultural-heritage-list }\end{array}$ & Legit \\
\hline $\begin{array}{l}\text { The Saudi women detained for demanding basic hu- } \\
\text { man rights }\end{array}$ & $\begin{array}{l}\text { https://www.aljazeera.com/news/2018/11/29/the-saudi- } \\
\text { women-detained-for-demanding-basic-human-rights/ }\end{array}$ & Legit \\
\hline $\begin{array}{l}\text { Georgia ruling party candidate Zurabishvili wins pres- } \\
\text { idential runoff }\end{array}$ & $\begin{array}{l}\text { https://www.aljazeera.com/news/2018/11/30/ex-envoy- } \\
\text { wins-georgia-presidency-vote-to-be-challenged }\end{array}$ & Legit \\
\hline
\end{tabular}

Table 2 - The manually selected 20 news dataset (10 fake and 10 true news) for manual experiment. Fake news were selected from the top 50 fake news of 2018 according to BuzzFeed. Legit news were selected from NELA-GT-2018 dataset. 


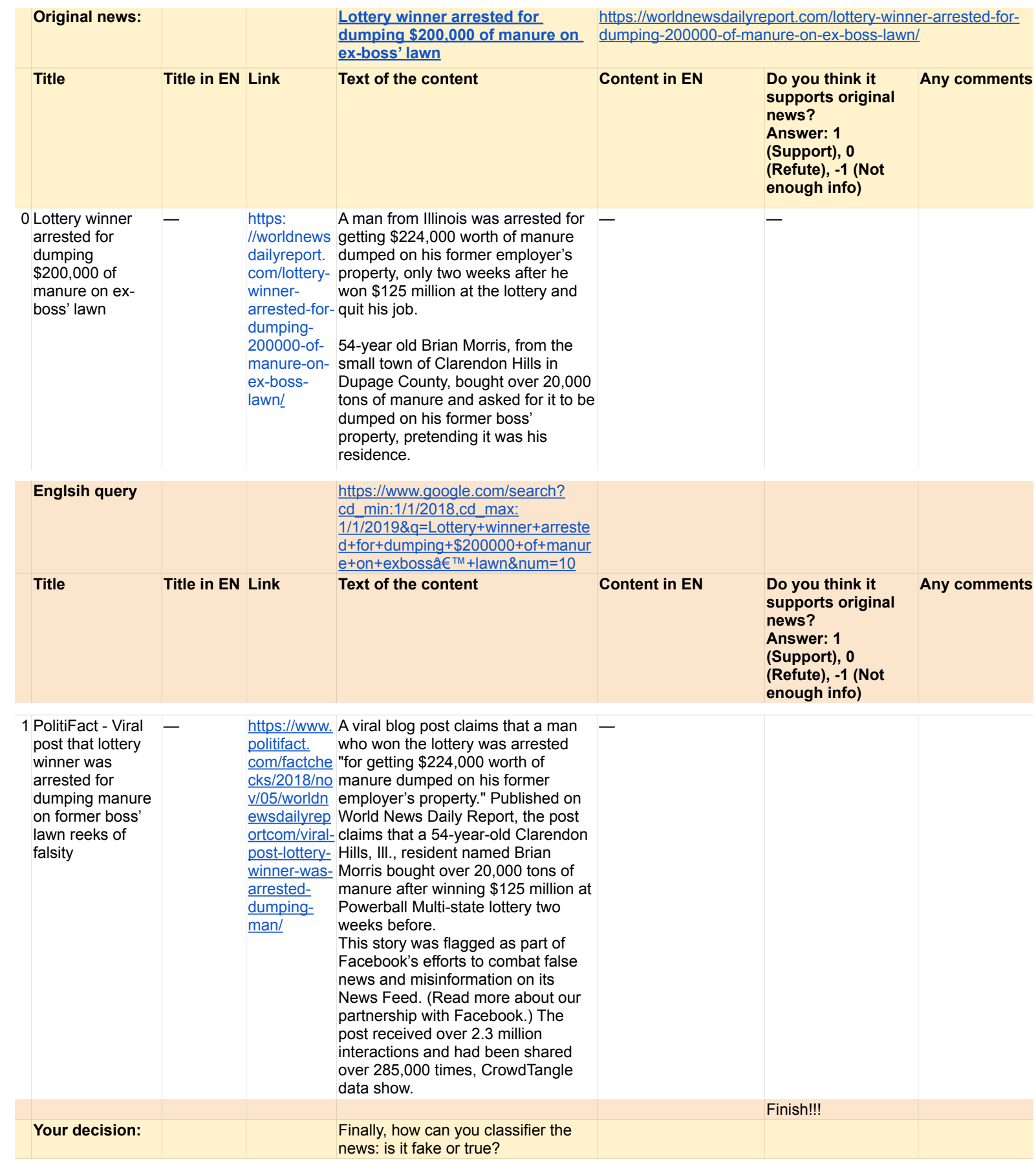

Figure 3 - User interface that was used for annotators answer collection for manual verification. An annotator has to conduct Step 4 and Step 5 of the pipeline: (i) identify whether a cross-lingual scraped news supports, refutes or has not enough info with respect to the original one; (ii) classify the original news as a fake or a true one based on the provided cross-lingual evidence. 


\section{B Samples of Cross-lingual Evidence for News Items}

\begin{tabular}{|c|c|}
\hline Title & English translation \\
\hline \multicolumn{2}{|c|}{ Original news (FAKE) } \\
\hline Kate Middleton \& Prince William Try To Save Crumbling Marriage? & - \\
\hline \multicolumn{2}{|c|}{ English search results } \\
\hline Prince William and Kate Middleton's Love Through the Years & - \\
\hline $\begin{array}{l}\text { How Princess Diana made desperate 'last-ditch attempt' to save marriage } \\
\text { with Charles }\end{array}$ & - \\
\hline $\begin{array}{l}\text { Prince William of Wales - Economist - World News, Politics, Economics, } \\
\text { Business \& Finance }\end{array}$ & - \\
\hline \multicolumn{2}{|c|}{ French search results } \\
\hline Le jour où le prince William a demandé Kate Middleton en mariage & The day Prince William proposed to Kate Middleton \\
\hline William et Kate, fiançailles avant le mariage royal & William and Kate, engagement before the royal wedding \\
\hline Mariage William et Kate & William and Kate wedding \\
\hline \multicolumn{2}{|c|}{ German search results } \\
\hline $\begin{array}{l}\text { Elternschaft, Babynamen, Prominente und königliche Nachrichten - } \\
\text { CafeMom.com }\end{array}$ & Parenting, Baby Names, Celebrities, and Royal News — CafeMom.com \\
\hline Kate Middletons umstrittenste Momente aller Zeiten & Kate Middleton's Most Controversial Moments of All Time \\
\hline Wie Kate Middleton und Prinz William das Leben ihrer Kinder normal halten & How Kate Middleton and Prince William Keep Their Kids' Lives Normal \\
\hline \multicolumn{2}{|c|}{ Spanish search results } \\
\hline Príncipe William - Clarín.com & Prince William - Clarín.com \\
\hline Con un comentario, Harry hizo llorar a Kate Middleton en el día de su boda & With a comment, Harry made Kate Middleton cry on his wedding day \\
\hline $\begin{array}{l}\text { El Príncipe Guillermo de Inglaterra se casará con su novia Kate Middleton } \\
\text { en } 2011 \text { - RTVE.es }\end{array}$ & $\begin{array}{l}\text { Prince William of England will marry his girlfriend Kate Middleton in } 2011 \\
\text { - RTVE.es }\end{array}$ \\
\hline \multicolumn{2}{|c|}{ Russian search results } \\
\hline $\begin{array}{l}\text { Факты о свадьбе Кейт Миддлтон и принца Уильяма, о ко- } \\
\text { торых вы могли не знать }\end{array}$ & Kate Middleton and Prince William's wedding facts you might not know \\
\hline Кейт Миддлтон & Kate Middleton \\
\hline Кэтрин, герцогиня Кембриджская - Википедия & Catherine, Duchess of Cambridge - Wikipedia \\
\hline \multicolumn{2}{|c|}{ Original news (LEGIT) } \\
\hline Amazon Prime Air drone completes its first US public delivery & - \\
\hline \multicolumn{2}{|c|}{ English search results } \\
\hline Amazon Prime Air drone completes its first US public delivery & - \\
\hline $\begin{array}{l}\text { Amazon's Prime Air drone delivery fleet gains FAA approval for trial com- } \\
\text { mercial flights - TechCrunch }\end{array}$ & - \\
\hline Amazon completes its first public US drone delivery & - \\
\hline \multicolumn{2}{|c|}{ French search results } \\
\hline E-commerce. Amazon autorisé à livrer par drone aux États-Unis & E-commerce. Amazon authorized to deliver by drone to the United States \\
\hline Première livraison par drone réussie pour Amazon & First successful drone delivery for Amazon \\
\hline Amazon a livré son premier colis par drone & Amazon delivered its first package by drone \\
\hline \multicolumn{2}{|c|}{ German search results } \\
\hline Prime Air: FAA erteilt Amazons Lieferdrohnen die Starterlaubnis & Prime Air: FAA gives Amazon's delivery drones permission to take off \\
\hline $\begin{array}{l}\text { Amazon Prime Air-Drohne schließt erste öffentliche Auslieferung in den } \\
\text { USA ab }\end{array}$ & Amazon Prime Air drone completes first US public delivery \\
\hline $\begin{array}{l}\text { Amazon Prime Air: Amazon kündigt Lieferungen per Drohne binnen } \\
\text { Monaten an }\end{array}$ & Amazon Prime Air: Amazon announces drone deliveries within months \\
\hline \multicolumn{2}{|c|}{ Spanish search results } \\
\hline Amazon hace su primera entrega por dron en Estados Unidos & Amazon makes its first delivery by drone in the United States \\
\hline Amazon recibe autorización para operar entregas con drones & Amazon receives authorization to operate drone deliveries \\
\hline $\begin{array}{l}\text { Amazon recibe aprobación federal para arrancar Prime Air, su propuesta de } \\
\text { entrega con drones }\end{array}$ & $\begin{array}{l}\text { Amazon receives federal approval to launch Prime Air, its drone delivery } \\
\text { proposal }\end{array}$ \\
\hline \multicolumn{2}{|c|}{ Russian search results } \\
\hline Amazon запускает дроны Prime Air для быстрой доставки & Amazon launches Prime Air drones for fast delivery \\
\hline $\begin{array}{l}\text { В США прошла первая публичная демонстрация доставки } \\
\text { товара с помощью дронов Amazon Prime Air }\end{array}$ & $\begin{array}{l}\text { First Public Demonstration of Amazon Prime Air Product Delivery Held in } \\
\text { USA }\end{array}$ \\
\hline $\begin{array}{l}\text { Amazon показала новые гибридные дроны для доставки } \\
\text { заказов сервиса Prime Air }\end{array}$ & Amazon Shows New Hybrid Drones To Deliver Prime Air Orders \\
\hline
\end{tabular}

Table 3 - The example of the cross-lingual evidence extraction for fake and legit news from FakeNewsAMT. For each target language (English, French, German, Spanish, Russian) search results are presented: titles of top 3 news. For every non-Enlgish title the English translation is provided. For fake news the search results across other languages are only mildly topically related to the original news while for legit news the search results across other languages are strongly related to the original news. 


\begin{tabular}{|c|c|}
\hline Title & English translation \\
\hline \multicolumn{2}{|c|}{ Original news (FAKE) } \\
\hline В Израиле создали лекарство от коронавируса: & Israel invented a vaccine against coronavirus \\
\hline https://www.vesty.co.il/article/SJxK1wRF8 & \\
\hline \multicolumn{2}{|c|}{ English search results } \\
\hline Israel isolates coronavirus antibody in 'significant breakthrough' & - \\
\hline Israel is not releasing a coronavirus vaccine - The Forward & - \\
\hline Hadassah treats COVID-19 patient with new concentrated passive vaccine & - \\
\hline \multicolumn{2}{|c|}{ French search results } \\
\hline Les Israéliens et le vaccin contre le coronavirus & The Israelis and the coronavirus vaccine \\
\hline Pandémie de Covid-19 en Israël — Wikipédia & Covid-19 pandemic in Israel - Wikipedia \\
\hline Vaccin contre la Covid-19 - Wikipédia & Vaccin contre la Covid-19 - Wikipédia \\
\hline \multicolumn{2}{|c|}{ German search results } \\
\hline Impfstoffe gegen Coronavirus - aktueller Forschungsstand & Coronavirus vaccines - current state of research \\
\hline Warum es so lang dauert, einen Corona-Impfstoff zu entwickeln & Why it takes so long to develop a corona vaccine \\
\hline Falschinformationen zur COVID-19-Pandemie - Wikipedia & Incorrect information about the COVID-19 pandemic - Wikipedia \\
\hline \multicolumn{2}{|c|}{ Spanish search results } \\
\hline $\begin{array}{l}\text { Cuáles son y en qué estado están los esfuerzos israelíes para inventar una } \\
\text { vacuna para el coronavirus }\end{array}$ & What are a \\
\hline Sus mejores intentos ... - Consulado General H. de Israel & Your best attempts ... - Consulate General H. of Israel \\
\hline Vacuna de Pfizer y BioNTech muestra resultados positivos & Pfizer and BioNTech vaccine shows positive results \\
\hline \multicolumn{2}{|c|}{ Russian search results } \\
\hline $\begin{array}{l}\text { В Израиле заявили, что Covid-19 остановит лекарство от } \\
\text { холестерина }\end{array}$ & Israel says cholesterol medication will stop Covid-19 \\
\hline $\begin{array}{l}\text { Врач о Covid-19: «Мы не понимаем патогенез заболевания» } \\
\text { - Израиль в фокусе }\end{array}$ & $\begin{array}{l}\text { Doctor about Covid-19: } \ll \text { We do not understand the pathogenesis of the } \\
\text { disease } \gg \text { - Israel in focus }\end{array}$ \\
\hline Израильские технологии & Israeli technology \\
\hline \multicolumn{2}{|c|}{ Original news (LEGIT) } \\
\hline $\begin{array}{l}\text { В Монголии произошла } \\
\text { https://hightech.fm } / 2020 / 07 / 02 / \text { plague-outbreak }\end{array}$ & Bubonic plague outbreak in Mongolia \\
\hline \multicolumn{2}{|c|}{ English search results } \\
\hline Bubonic plague: Case found in China's Inner Mongolia - CNN & - \\
\hline Teenager dies of Black Death in Mongolia & - \\
\hline China bubonic plague: Inner Mongolia takes precautions after case & - \\
\hline \multicolumn{2}{|c|}{ French search results } \\
\hline Epidémie : des cas de peste détectés en Chine et en Mongolie & Epidemic: cases of plague detected in China and Mongolia \\
\hline $\begin{array}{l}\text { Craintes d'une épidémie de peste bubonique? Un adolescent de } 15 \text { ans est la } \\
\text { première victime recensée en Mongolie }\end{array}$ & $\begin{array}{l}\text { Fear of a bubonic plague epidemic? A } 15 \text {-year-old is the first victim in Mon- } \\
\text { golia }\end{array}$ \\
\hline Chine : Un cas de peste bubonique détecté en Mongolie intérieure & China: Bubonic plague case detected in Inner Mongolia \\
\hline German s & rch results \\
\hline Mongolei: 15-Jähriger an Beulenpest gestorben - DER SPIEGEL & Mongolia: 15-year-old died of bubonic plague - DER SPIEGEL \\
\hline Beulenpest - Was über die Pest-Fälle in China bekannt & Bubonic plague - what is known about the plague cases in China \\
\hline Bringen Murmeltiere die Pest zurück? Mongolei warnt vor Tier-Kontakt & Will marmots bring the plague back? Mongolia warns of animal contact \\
\hline Spanish s & rch results \\
\hline BROTE DE PESTE BUBÓNICA EN MONGOLIA & BUBONIC PLAGUE OUTBREAK IN MONGOLIA \\
\hline Brote de peste negra provoca cuarentena en Mongola & Black plague outbreak causes quarantine in Mongolia \\
\hline Brote de peste negra alarma en Mongolia y cierra frontera con Rusia & Black plague outbreak alarms Mongolia, closes border with Russia \\
\hline Russian s & rch results \\
\hline $\begin{array}{l}\text { В Монголии произошла вспышка бубонной чумы ... - Гор- } \\
\text { дон }\end{array}$ & There was an outbreak of bubonic plague in Mongolia ... - Gordon \\
\hline $\begin{array}{l}\text { В Монголии произошла вспышка бубонной чумы - } \\
\text { Урал56.Ру }\end{array}$ & Bubonic plague outbreak in Mongolia - Ural56.Ru \\
\hline $\begin{array}{l}\text { Возвращение «Черной смерти»: главное о вспышке бубон- } \\
\text { ной чумы в Монголии }\end{array}$ & $\begin{array}{l}\text { Return of the "Black Death": the main thing about the outbreak of the } \\
\text { bubonic plague in Mongolia }\end{array}$ \\
\hline
\end{tabular}

Table 4 - The result of the cross-lingual evidence extraction for real-life news. For each target language (English, French, German, Spanish, Russian) search results are presented: titles of top 3 news. For every non-Enlgish title the English translation is provided. For fake news the search results across other languages are only mildly topically related to the original news while for legit news the search results across other languages are strongly related to the original news. 